\title{
Unbiased data mining identifies cell cycle transcripts that predict non-indolent Gleason score 7 prostate cancer
}

\author{
Wendy L. Johnston ${ }^{1 *}$ (D), Charles N. Catton ${ }^{1,2}$ and Carol J. Swallow $3,4,5,6$
}

\begin{abstract}
Background: Patients with newly diagnosed non-metastatic prostate adenocarcinoma are typically classified as at low, intermediate, or high risk of disease progression using blood prostate-specific antigen concentration, tumour T category, and tumour pathological Gleason score. Classification is used to both predict clinical outcome and to inform initial management. However, significant heterogeneity is observed in outcome, particularly within the intermediate risk group, and there is an urgent need for additional markers to more accurately hone risk prediction. Recently developed web-based visualization and analysis tools have facilitated rapid interrogation of large transcriptome datasets, and querying broadly across multiple large datasets should identify predictors that are widely applicable.

Methods: We used camcAPP, CBioPortal, CRN, and NIH NCI GDC Data Portal to data mine publicly available large prostate cancer datasets. A test set of biomarkers was developed by identifying transcripts that had: 1) altered abundance in prostate cancer, 2) altered expression in patients with Gleason score 7 tumours and biochemical recurrence, 3) correlation of expression with time until biochemical recurrence across three datasets (Cambridge, Stockholm, MSKCC). Transcripts that met these criteria were then examined in a validation dataset (TCGA-PRAD) using univariate and multivariable models to predict biochemical recurrence in patients with Gleason score 7 tumours.
\end{abstract}

Results: Twenty transcripts met the test criteria, and 12 were validated in TCGA-PRAD Gleason score 7 patients. Ten of these transcripts remained prognostic in Gleason score $3+4=7$, a sub-group of Gleason score 7 patients typically considered at a lower risk for poor outcome and often not targeted for aggressive management. All transcripts positively associated with recurrence encode or regulate mitosis and cell cycle-related proteins. The top performer was BUB1, one of four key MIR145-3P microRNA targets upregulated in hormone-sensitive as well as castration-resistant PCa. SRD5A2 converts testosterone to its more active form and was negatively associated with biochemical recurrence.

Conclusions: Unbiased mining of large patient datasets identified 12 transcripts that independently predicted disease recurrence risk in Gleason score 7 prostate cancer. The mitosis and cell cycle proteins identified are also implicated in progression to castration-resistant prostate cancer, revealing a pivotal role for loss of cell cycle control in the latter.

Keywords: Prostate cancer prognosticators, Gleason $3+4=7$ prostate cancer, Biochemical recurrence, Castrationresistant prostate cancer, Biomarker, HES6, E2F2, Cell cycle, BUB1, SRD5A2

\footnotetext{
* Correspondence: wendyjohnstonchitin@gmail.com

${ }^{1}$ Radiation Medicine Program, Princess Margaret Cancer Centre, University

Health Network, Toronto, ON, Canada

Full list of author information is available at the end of the article
}

(c) The Author(s). 2019 Open Access This article is distributed under the terms of the Creative Commons Attribution 4.0 International License (http://creativecommons.org/licenses/by/4.0/), which permits unrestricted use, distribution, and reproduction in any medium, provided you give appropriate credit to the original author(s) and the source, provide a link to the Creative Commons license, and indicate if changes were made. The Creative Commons Public Domain Dedication waiver (http://creativecommons.org/publicdomain/zero/1.0/) applies to the data made available in this article, unless otherwise stated. 


\section{Background}

In developed countries, prostate cancer (PCa) is the most commonly diagnosed non-skin cancer in men and a leading cause of cancer death $[1,2]$. Data compiled in 2010 for Canadian men, for example, showed a 14.1\% lifetime risk for developing $\mathrm{PCa}$, and a $3.5 \%$ probability of dying from $\mathrm{PCa}$ [3]. As such, $\mathrm{PCa}$ is second only to lung and bronchus for cancer-related mortality in men.

In $\mathrm{PCa}$ patients who have had their prostate removed, biochemical recurrence (BCR) of blood prostate-specific antigen (PSA) occurs in 20-40\% of cases within 10-15 years [4-6]. BCR is commonly used as a surrogate for metastatic PCa, since it is a necessary antecedent [7]. However, BCR can occur without radiological evidence of metastasis, and the reported $\mathrm{PCa}$-specific mortality in patients with BCR is only $19-45 \%$ by $10-15$ years $[4,6,8]$. Prostate tissue is androgen-sensitive, and treatments for metastatic PCa typically include androgen-deprivation. While initially successful, within 2 years $\sim 70 \%$ of metastatic $\mathrm{PCa}$ becomes resistant to androgen deprivation (castration-resistant $\mathrm{PCa}[\mathrm{CRPC}])$, leading, almost invariably, to PCa-specific mortality (reviewed in [9]). Given the heterogeneous outcome in patients diagnosed with localized $\mathrm{PCa}$, risk stratification of newly diagnosed patients with non-metastatic disease at presentation is critical to inform clinical management, and treatment options include observation and one or more of radical prostatectomy, radiotherapy, and androgen deprivation therapy [10, 11].

Twenty years ago, D'Amico and colleagues [12] proposed a classification scheme assessing risk for BCR following radical prostatectomy based on PSA, Gleason score and tumour category. Low risk was defined as PSA $<10 \mathrm{ng} / \mathrm{ml}$, Gleason score $<6$, and tumour T1-T2a; intermediate risk as PSA 10-20 ng/ml, and/or Gleason score 7, and/or T2b; and high risk as PSA > $20 \mathrm{ng} / \mathrm{ml}$ and/or Gleason score 8-10 and/or $>$ T2c. Tumour sub-staging has since been abolished by the AJCC Eighth Edition and by the International Society for Urologic Pathology (https://www.ncbi.nlm.nih.gov/pubmed/27251951). However, tumours can still be stratified within groups; for example, patients with Gleason score 7 tumours are frequently sub-classified into $3+4=7$ (3, primary, 4 ; secondary, patterns), or $4+3=7$, since $3+4=7$ has a 3 -fold lower risk of lethal outcome than $4+3=7$ [13]. Despite these refinements, significant heterogeneity is apparent in the observed incidence of $\mathrm{BCR}$ and the more clinically relevant $\mathrm{PCa}$-specific mortality. Heterogeneity is particularly evident for intermediate risk patients, who comprise the largest group [14, 15]. Enhanced discrimination amongst these patients would facilitate more tailored management. As such, new biomarkers are required to accurately identify patients who are at a higher risk for aggressive disease and therefore merit more aggressive treatment, while at the same time allowing for patients with more indolent disease to be observed. Of particular interest are biomolecule markers isolated from tumours, blood, or urine, including proteins, coding and non-coding RNA, and genetic and epigenetic modifications. Unbiased co-discovery of molecules that act in shared cellular pathways might also suggest particularly vulnerable cell signaling pathways to target for therapeutic intervention.

Next generation sequencing with public sharing of data has yielded an enormous amount of genomic and transcriptomic information that is now available to $\mathrm{PCa}$ researchers worldwide [16, 17]. An unprecedented and still emerging picture of genome alterations, epigenetic landscape, and gene and protein expression in tumours and normal tissue has enabled the development of a number of PCa prognostic systems (reviewed in [18-20]). Interestingly, there is not much overlap between most previously identified biomarkers [20]. This may reflect, in part, different strategies for biomarker discovery. For example, some studies have queried restricted groups of genes (e.g., a subset of cell cycle genes [21], annotated PCa-associated genes [22], miRNA-regulated transcripts [23]), or different cell types (e.g. stromal cells [24]).

In this study, we exploit recently developed webbased tools and publicly available PCa transcriptome data to perform an unbiased query of multiple datasets, focusing on Gleason score 7 PCa. We identify 12 transcripts that predicted BCR (1 downregulated, 11 upregulated in tumours). Ten of these transcripts remained prognostic for poor outcome in patients with Gleason score $3+4=7 \mathrm{PCa}$. Importantly, this suggests a possible strategy to identify higher risk patients within a group that is, overall, considered at a low to intermediate risk for poor outcome. Multivariable logistic regression analysis within the $3+4=7$ group showed combining either UBE2C or CCNB1, which are elevated in $\mathrm{PCa}$, with SRD5A2, which is decreased in $\mathrm{PCa}$, increased the prognostic power over and above any of the 3 transcripts alone. Ten of the 11 Gleason 7 (and all of the Gleason $3+$ $4=7$ sub-group) upregulated biomarkers are mitosis and cell cycle related genes that are also part of an E2F1 transcription-factor regulated cell cycle network that predicts lethal metastatic CRPC [25]. Therefore, in addition to predicting $\mathrm{BCR}$, they are prognostic for $\mathrm{PCa}$-specific mortality. Future studies comparing the performance of these transcripts with other biomarkers in new datasets will help determine their robustness in predicting, and potentially treating, non-indolent $\mathrm{PCa}$.

\section{Methods}

A set of test transcripts was identified in an unbiased, stepwise fashion using 3 free, publicly available webbased data visualization and analysis tools that enable rapid genome-wide screening (Fig. 1a). In step 1, Cancer 

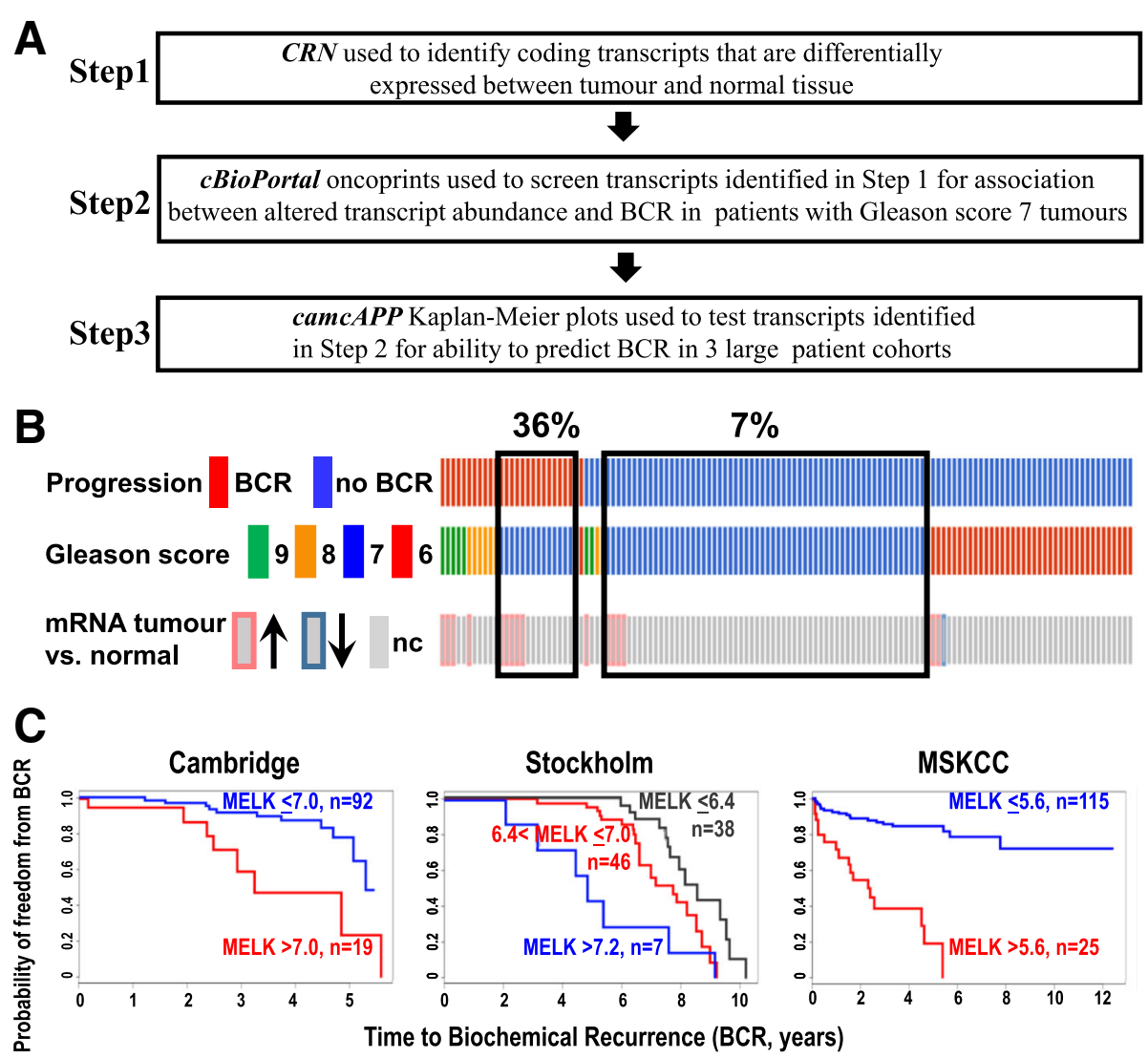

Fig. 1 Rapid generation of a transcript test set using 3 web-based tools: CRN, cBioPortal, and camcAPP. a) Outline of steps used to generate the transcript test set. b) cBioPortal oncoprint (step 2) example (MELK) indicates 36\% of patients with Gleason score 7 tumours who experienced biochemical recurrence (BCR) had increased MELK transcript. In contrast, only $7 \%$ of those who remained BCR-free had increased transcript. Patients (individual bars) are aligned within the three rows. nc- no difference in tumour transcript abundance compared with normal tissue. c) camcAPP Kaplan-Meier plots (step 3) example (MELK) shows higher MELK expression is associated with shorter time to BCR in all three datasets. Grouping of samples determined by recursive partitioning (Hothorn et al., 2006). b, c) MSKCC data from Taylor et al., 2010. c) Cambridge and Stockholm data from Ross-Adams et al., 2015

RNA-Seq Nexus (CRN) TCGA-PRAD data (http://syslab 4.nchu.edu.tw/) [26] was used to identify genes that had at least one isoform with altered transcript abundance in tumours, compared to normal controls $(p<1.0 \mathrm{E}-04)$. DAVID 6.8 Gene Name Batch Viewer (https://david.ncifcrf.gov/list.jsp) [27, 28] was used to remove duplicates. In step 2, genes identified in step 1 were queried for patient BCR status, tumour transcript abundance (z-score threshold of 2.0), and tumour Gleason score using cBioPortal, (http://www.cbioportal.org/) [29, 30] MSKCC 2010 data [31]. MSKCC data was used since it is the only cBioPortal prostate cancer dataset in which tumour transcript abundance is compared to normal tissue (other datasets compare patient tumour sample transcript abundance to all tumours that are diploid). In this cohort, 131 patients had primary tumour transcript data available, with 27 of these patients experiencing BCR. Of the 27, 14 had Gleason score 7 tumours and 4 had PSA $10-20 \mathrm{ng} / \mathrm{ml}$. Taking into account the limited number of patients who experienced BCR, we chose to screen transcript abundance in patients with Gleason score 7 tumours. Batches of oncoprints for 50 genes were examined manually to identify transcripts that were increased or decreased in Gleason score 7 patients with BCR, compared to Gleason score 7 patients who remained free of BCR (Fig. 1b shows MELK as an example). In step 3, transcripts identified in Step 2 were then examined using camcAPP (http://bioinformatics.cruk.cam.ac.uk/apps/camcAPP/) [32]. Kaplan-Meier plots examining the relationship between transcript abundance and time to $\mathrm{BCR}$ were generated for each transcript using Cambridge, Stockholm, [33] and MSKCC [31] data (Fig. 1c shows MELK as an example). Genes for which the time to BCR could be separated by recursive partitioning [34] into distinct transcript abundance groups for all three datasets were designated the test set.

Expression (transcript per million; TPM) of test genes was examined in TCGA-PRAD normal tissues $(n=52)$, and tumours for which transcript abundance, BCR 
status, and reviewed Gleason score were available $(n=$ 285 ). Details of sample acquisition and processing following radical prostatectomy at authorized tissue source sites are provided by TCGA-PRAD [35]. Reviewed Gleason score (assigned by TCGA genitourinary pathologists on prostatectomy specimens) was used to avoid possible collection site variability in scoring. Samples with zero or near zero (TPM $<1.6 \mathrm{E}-07)$ transcript abundance were removed from the analysis; these included 1 normal for DLGAP5 and CDK1, 3 normals for E2F2 and MELK, and 5 normals and 6 tumours for CDKN3. Univariate logistic regression (SAS 9.4) was performed to determine odds ratios (ORs), and ROC-AUC was calculated for each of the test transcripts, as well as for Gleason score and pre-operative PSA using easyROC http://www.biosoft.hacettepe.edu.tr/easyROC/ [36]. Multivariable logistic regression was performed on transcripts with increased abundance and ORs having $p$ values $<0.05$, and SRD5A2, which had decreased abundance, in Gleason score $7(n=158)$, Gleason score $4+3=7 \quad(n=70)$ and Gleason score $3+4=7(n=88)$ tumours. The multivariable model was restricted to include only 2 independent variables due to the limited number $(n=13)$ of BCR events in patients with Gleason score 7 tumours. Pre-operative PSA concentration was only available for a subset of patients $(88 / 156)$ that included only 4 patients with BCR, so was not included in the multivariable analysis. Future studies that include more samples with longer term follow-up (and hence, more BCR) will be helpful to test the independent contributions of PSA in patients with Gleason score 7 tumours.

Transcripts identified in the current study were examined for overlap with previously reported prognostic transcript signatures [21-23, 25, 33, 37-56]. Gene names were standardized using GeneCards http://www.genecards.org/ v4.5.0 Build 38, except for TSBP, for which 2 aliases were listed in GeneCards (CTR9, c6orf10), and Gene Ontology (GO terms) were determined using DAVID $6.8 \mathrm{https://}$ david.ncifcrf.gov/home.jsp [27, 28]. Proportional Venn diagrams were generated using euler $A P E$ http://www.eulerdiagrams.org/eulerAPE [57].

\section{Results}

A comparison of prostate cancer primary tumours $(n=$ $497)$ vs. normal prostatic tissue samples $(n=52)$ revealed altered transcript abundance of at least one isoform of 8187 genes (Additional file 1: Table S1). Manual examination of these 8187 genes in MSKCC Gleason score 7 patients using cBioPortal oncoprints identified 1816 genes with differences in expression between patients without BCR $(n=60)$ and those with BCR $(n=14)$ (Additional file 1: Table S2). For each of the 1816 genes identified by the above algorithm, the Cambridge $(n=111)$, Stockholm $(n=92)$, and MSKCC $(n=140)$ datasets were interrogated for any correlation between transcript abundance and BCR-free survival across all Gleason scores. The level of expression of twenty-two individual genes predicted BCR-free survival in all three of the patient cohorts (Table 1). Two of these genes were eliminated from the test set due to discordance in the expression differential between data sets. In particular, for ANKMY1, higher BCR-free survival was observed in association with lower expression in the Cambridge and MSKCC datasets, but with higher expression in the Stockholm dataset. In the case of ALDH1A2, there were discordant results between the MSKCC cohort of Gleason score 7 patients queried using cBioPortal, and the group of patients in the Cambridge, Stockholm, and MSKCC datasets examined using camcAPP. The final test set of 20 transcripts included 13 with higher expression in tumour vs. normal tissue that were positively associated with $\mathrm{BCR}$, and 7 with decreased expression in tumours that were negatively associated with BCR (Table 1).

When examined across Gleason scores 6 through 10, 14 of 20 test set genes yielded an OR, and 17 an ROC-AUC, that was prognostic $(p<.05)$ for BCR in the TCGA-PRAD validation dataset $(n=285)$ (Additional file 1: Table S3). For half of the genes, the AUC was greater than for Gleason score or pre-operative PSA, examined in the same group of patients (Additional file 2). Within the group of Gleason score 7 patients in the TCGA-PRAD dataset $(n=$ 158), 12 transcripts remained prognostic (Table 2, Fig. 2), with 1 negatively associated with BCR (SRD5A2) and 11 positively associated with BCR (BUB1, TPX2, NCAPG, UBE2C, MELK, CCNA2, CCNB1,CDK1, E2F2, DLGAP5, TMEM206,). Ten of the 11 transcripts positively associated with BCR encode proteins that are functionally annotated as related to mitotic and cell cycle (GO:0000082, GO:0051726), cell division (GO:0051301), or cell proliferation (GO:0008283). The proteins they encode also participate in an E2F1-dependent cell cycle network associated with CRPC, and 4 of the 11 (BUB1, NCAPG, CDK1, MELK) are implicated in miRNA (MIR145-3P)-dependent CRPC (Fig. 3). The 11th transcript encodes a membrane protein (TMEM206) that has recently been identified as important to control cell proliferation in colorectal cancer cells [58].

Ten of 12 transcripts that were prognostic in Gleason score 7 tumours remained prognostic in patients with Gleason $3+4=7$ tumours (Table 3), and multivariable logistic regression analysis showed that combining CCNB1 or UBE2C with SRD5A2 slightly improved the predictive power of the model (Additional file 1: Table S4). In low risk (Gleason score 6) tumours, 9 transcripts remained prognostic, although the limited number of cases of BCR $(n=3)$ in this group may limit its predictive power (Additional file 1: Table S5). Interestingly, in Gleason $4+3=7$, only TMEM206 was prognostic (Additional 
Table 1 Test set of 20 transcripts that predicted time until BCR

\begin{tabular}{|c|c|c|c|c|c|c|c|c|}
\hline \multirow[b]{2}{*}{ Transcript* } & \multirow[b]{2}{*}{ Chromosomal location } & \multirow[b]{2}{*}{ Fold change $e^{c}$} & \multicolumn{2}{|c|}{ Cambridge $(n=111)$} & \multicolumn{2}{|c|}{ Stockholm $(n=92)$} & \multicolumn{2}{|c|}{$\operatorname{MSKCC}(n=140)$} \\
\hline & & & $p$ value & $\mathrm{RP}_{\text {cutoff }}{ }^{\mathrm{d}}$ & $p$ value & $\overline{\text { RP } \text { cutoff }^{d}}$ & $p$ value & RP cutoff ${ }^{d}$ \\
\hline TPX2 & $20 q 11.21$ & 3.0 & $4.80 \mathrm{E}-05$ & $<6.96$ & $5.40 \mathrm{E}-02$ & $<6.45$ & 5.10E-07 & $<6.38$ \\
\hline BUB1 & $2 q 13$ & 2.8 & $1.10 \mathrm{E}-02$ & $<6.26$ & $9.10 \mathrm{E}-03$ & $<6.36$ & $9.40 \mathrm{E}-07$ & $<6.27$ \\
\hline CCNA2 & $4 q 27$ & 2.5 & $1.00 \mathrm{E}-02$ & $<6.99$ & 8.70E-03 & $<7.16$ & $6.70 \mathrm{E}-06$ & $<6.91$ \\
\hline E2F2 & $1 p 36.12$ & 1.9 & $2.90 \mathrm{E}-03$ & $<7.04$ & 4.10E-02 & $<6.62$ & $1.40 \mathrm{E}-02$ & $<9.99$ \\
\hline UBE2C & $20 q 13.12$ & 3.4 & $1.80 \mathrm{E}-03$ & $<7.52$ & 5.80E-03 & $<8.15$ & $2.00 \mathrm{E}-06$ & $<6.62$ \\
\hline NCAPG & $4 p 15.31$ & 2.7 & $2.70 \mathrm{E}-02$ & $<6.63$ & 4.60E-03 & $<6.77$ & $5.50 \mathrm{E}-07$ & $<6.02$ \\
\hline CDK1 & $10 q 21.2$ & 2.1 & $3.70 \mathrm{E}-03$ & $<7.13$ & $2.20 \mathrm{E}-03$ & $<7.13$ & $1.40 \mathrm{E}-04$ & $<4.95$ \\
\hline CDKN3 & $14 q 22.2$ & 2.4 & $1.50 \mathrm{E}-02$ & $<6.83$ & 4.50E-03 & $<7.01$ & 1.60E-07 & $<5.12$ \\
\hline DLGAP5 & $14 q 22.3$ & 3.4 & 4.90E-03 & $<6.61$ & 1.90E-02 & $<6.63$ & $2.90 \mathrm{E}-06$ & $<5.45$ \\
\hline MELK & $9 p 13.2$ & 3.3 & $2.40 \mathrm{E}-02$ & $<6.97$ & 6.60E-04 & $<6.45$ & $3.50 \mathrm{E}-06$ & $<5.6$ \\
\hline CCNB1 & $5 q 13.2$ & 1.8 & $1.60 \mathrm{E}-02$ & $<7.05$ & 3.00E-03 & $<6.83$ & 4.30E-04 & $<6.98$ \\
\hline TMEM206 & $1 q 32.3$ & 1.3 & $2.90 \mathrm{E}-02$ & $<7.87$ & $1.30 \mathrm{E}-02$ & $<7.22$ & $2.50 \mathrm{E}-03$ & $<7.66$ \\
\hline SHMT2 & $12 q 13.3$ & 1.7 & $3.20 \mathrm{E}-02$ & $<10.4$ & $3.50 \mathrm{E}-02$ & $<10.1$ & 1.10E-03 & $<8.57$ \\
\hline ANKMY $^{a}$ & $2 q 37.3$ & 1.03 & $4.90 \mathrm{E}-02$ & $<7.77$ & $2.20 \mathrm{E}-03$ & $>7.29$ & 2.70E-03 & $<8.11$ \\
\hline SRD5A2 & $2 \mathrm{p} 23.1$ & -3.7 & $9.10 \mathrm{E}-03$ & $>7.11$ & $1.70 \mathrm{E}-03$ & $>6.53$ & 1.60E-07 & $>7.05$ \\
\hline CSRP1 & $1 \mathrm{q} 32.1$ & -2.9 & 1.60E-02 & $>12$ & $2.30 \mathrm{E}-02$ & $>10.9$ & 2.00E-05 & $>9.55$ \\
\hline NFIB & 9p23-p22.3 & -1.1 & 7.30E-03 & $>11.5$ & $1.90 \mathrm{E}-02$ & $>11.15$ & 1.80E-04 & $>9.23$ \\
\hline PGM5 & $9 q 21.11$ & -3.6 & 5.70E-03 & $>8.59$ & $9.30 \mathrm{E}-03$ & $>10.8$ & 4.10E-07 & $>7.97$ \\
\hline CNN1 & 19p13.2 & -3.1 & $1.40 \mathrm{E}-02$ & $>8.99$ & 3.00E-02 & $>8.72$ & $2.40 \mathrm{E}-07$ & $>8.72$ \\
\hline DES & $2 q 35$ & -3.1 & $2.40 \mathrm{E}-02$ & $>9.53$ & 4.70E-02 & $>8.32$ & 2.70E-05 & $>8.99$ \\
\hline MPDZ & $9 p 23$ & -1.4 & 1.10E-02 & $>8.22$ & 1.10E-02 & $>7.44$ & $3.40 \mathrm{E}-03$ & $>8.43$ \\
\hline$A L D H 1 A 2^{b}$ & $15 q 21.3$ & -3.2 & 3.30E-02 & $>8.47$ & $2.50 \mathrm{E}-02$ & $>7.55$ & $6.40 \mathrm{E}-07$ & $>7.19$ \\
\hline
\end{tabular}

*The 20 transcripts shown in bold text were altered in tumours compared to normal tissue, and predicted time until BCR in Cambridge (Ross-Adams et al., 2015), Stockholm (Ross-Adams et al., 2015), and MSKCC (Taylor et al., 2010) datasets

${ }^{a} A N K M Y 1$ was excluded since results were discordant between the datasets

${ }^{\mathrm{b}} A L D H 1 A 2$ was excluded since results were discordant between cBioPortal and camcAPP portals

${ }^{c}$ total of all isoforms in tumour compared with normal (TCGA-PRAD)

d expression level cutoff for longer time to BCR, determined by recursive partitioning (RP) (Hothorn et al., 2006)

file 1: Table S6). The reason for the discrepancy between results for Gleason $3+4=7$ and $4+3=7$ is unclear. One possibility is that, with the exception of MELK, transcript abundance of positive prognosticators was higher in Gleason $3+4=7$ than in Gleason $4+3=7$ in patients with BCR (Additional file 1: Table S7). Future studies examining transcript abundance within regions of different pattern within the tumour may be helpful to explain these findings.

\section{Discussion}

$\mathrm{PCa}$ is a common disease with a heterogeneous clinical outcome that is difficult to predict using available risk stratification tools. Treatments such as prostatectomy, radiotherapy and androgen deprivation extend lifespan and improve the quality of life in patients with aggressive disease, but also cause unnecessary morbidity and loss of quality of life in those with indolent disease. Thus, a key goal in disease management is to develop biomarkers that accurately predict outcome. Variable outcome is especially evident in "intermediate risk" patients, making clinical decision-making particularly difficult within this group. To identify biomarkers that may be helpful for predicting outcome in this group, we took the approach of broadly querying publicly available transcriptome data using multiple distinct visualization and analysis data portals. We identify 12 genes, the expression of which predicted poor outcome (BCR) in patients with Gleason score 7 tumours. Eleven of the twelve genes have been identified as prognostic for $\mathrm{PCa}$ outcome in at least one other study (Additional file 1: Table S8), portending robustness. Importantly, $10 / 12$ of the genes remained prognostic in Gleason score $3+4=7$ tumours. Since Gleason $3+4=7$ tumours are often projected to have a more favourable prognosis [59], the identification of transcripts that may stratify this group into higher and lower risk of poor outcome may be particularly helpful for clinical decision-making.

The top performer we identified in Gleason score 7 tumours, including Gleason $3+4=7$, was BUB1. BUB1 
Table 2 Univariate logistic regression and ROC-AUC analyses for predicting BCR in patients with Gleason score 7 tumours

\begin{tabular}{|c|c|c|c|c|c|c|c|c|c|c|c|}
\hline Variable & Odds Ratio (OR) & $95 \% \mathrm{Cl}$ OR & $P$ value $\mathrm{OR}$ & ROC-AUC & SE AUC & $P$ value AUC & Youden cut-off & Sensitivity & Specificity & PPV & NPV \\
\hline \multicolumn{12}{|l|}{ (up in tumour) } \\
\hline BUB1 & 1.31 & $0.908-1.889$ & $1.48 \mathrm{E}-01$ & 0.720 & 0.055 & 5.35E-05 & 1.22 & 0.92 & 0.58 & 0.16 & 0.99 \\
\hline TPX2 & 1.18 & $0.994-1.406$ & 5.79E-02 & 0.732 & 0.066 & 4.53E-04 & 3.54 & 0.85 & 0.64 & 0.18 & 0.98 \\
\hline NCAPG & 1.51 & $0.913-2.510$ & 1.08E-01 & 0.711 & 0.065 & 1.08E-03 & 0.94 & 0.92 & 0.48 & 0.14 & 0.99 \\
\hline UBE2C & 1.07 & $0.998-1.142$ & 5.60E-02 & 0.713 & 0.067 & $1.42 \mathrm{E}-03$ & 7.79 & 0.69 & 0.69 & 0.17 & 0.96 \\
\hline MELK & 1.21 & $0.908-1.612$ & 1.93E-01 & 0.687 & 0.065 & 3.97E-03 & 1.82 & 0.69 & 0.69 & 0.17 & 0.96 \\
\hline CCNA2 & 1.27 & $0.967-1.680$ & 8.57E-02 & 0.694 & 0.069 & $5.04 \mathrm{E}-03$ & 2.58 & 0.69 & 0.70 & 0.17 & 0.96 \\
\hline CCNB1 & 1.13 & $0.954-1.345$ & 1.56E-01 & 0.685 & 0.066 & $5.20 \mathrm{E}-03$ & 4.60 & 0.92 & 0.48 & 0.14 & 0.99 \\
\hline CDK1 & 1.07 & $0.969-1.181$ & 1.81E-01 & 0.691 & 0.070 & $6.27 \mathrm{E}-03$ & 4.97 & 0.77 & 0.62 & 0.15 & 0.97 \\
\hline E2F2 & 2.84 & $0.715-11.309$ & 1.38E-01 & 0.682 & 0.068 & 7.55E-03 & 0.37 & 0.77 & 0.63 & 0.16 & 0.97 \\
\hline DLGAP5 & 1.24 & $0.766-2.014$ & $3.80 \mathrm{E}-01$ & 0.657 & 0.070 & $2.54 \mathrm{E}-02$ & 0.65 & 0.85 & 0.46 & 0.12 & 0.97 \\
\hline TMEM206 & 1.15 & $0.999-1.321$ & 5.10E-02 & 0.672 & 0.086 & 4.51E-02 & 9.11 & 0.85 & 0.52 & 0.14 & 0.97 \\
\hline CDKN3 & 1.14 & $0.936-1.387$ & $1.93 \mathrm{E}-01$ & 0.643 & 0.079 & $6.93 \mathrm{E}-02$ & 2.04 & 0.92 & 0.39 & 0.12 & 0.98 \\
\hline SHMT2 & 1.01 & $0.990-1.038$ & $2.52 \mathrm{E}-01$ & 0.605 & 0.069 & $1.25 \mathrm{E}-01$ & 56.64 & 0.69 & 0.57 & 0.13 & 0.95 \\
\hline \multicolumn{12}{|c|}{ (down in tumour) } \\
\hline SRD5A2 & 0.90 & $0.786-1.021$ & $9.85 \mathrm{E}-02$ & 0.674 & 0.079 & 2.70E-02 & 7.98 & 0.92 & 0.44 & 0.13 & 0.99 \\
\hline CSRP1 & 0.998 & $0.996-1.001$ & 1.30E-01 & 0.628 & 0.080 & 1.11E-01 & 417.97 & 0.54 & 0.72 & 0.15 & 0.95 \\
\hline PGM5 & 0.99 & $0.974-1.006$ & 2.04E-01 & 0.592 & 0.085 & 2.84E-01 & 22.95 & 0.39 & 0.81 & 0.15 & 0.94 \\
\hline NFIB & 0.98 & $0.941-1.029$ & $4.68 \mathrm{E}-01$ & 0.584 & 0.092 & $3.60 \mathrm{E}-01$ & 27.09 & 0.69 & 0.56 & 0.12 & 0.95 \\
\hline
\end{tabular}

Data are from TCGA-PRAD (TCGA, 2015). $n=158$. Cl-confidence interval, SE-standard error. Youden cut-off is the optimal point to separate biochemical recurrence $(B C R)$ from non-BCR. PPV-positive predictive value, NPV-negative predictive value

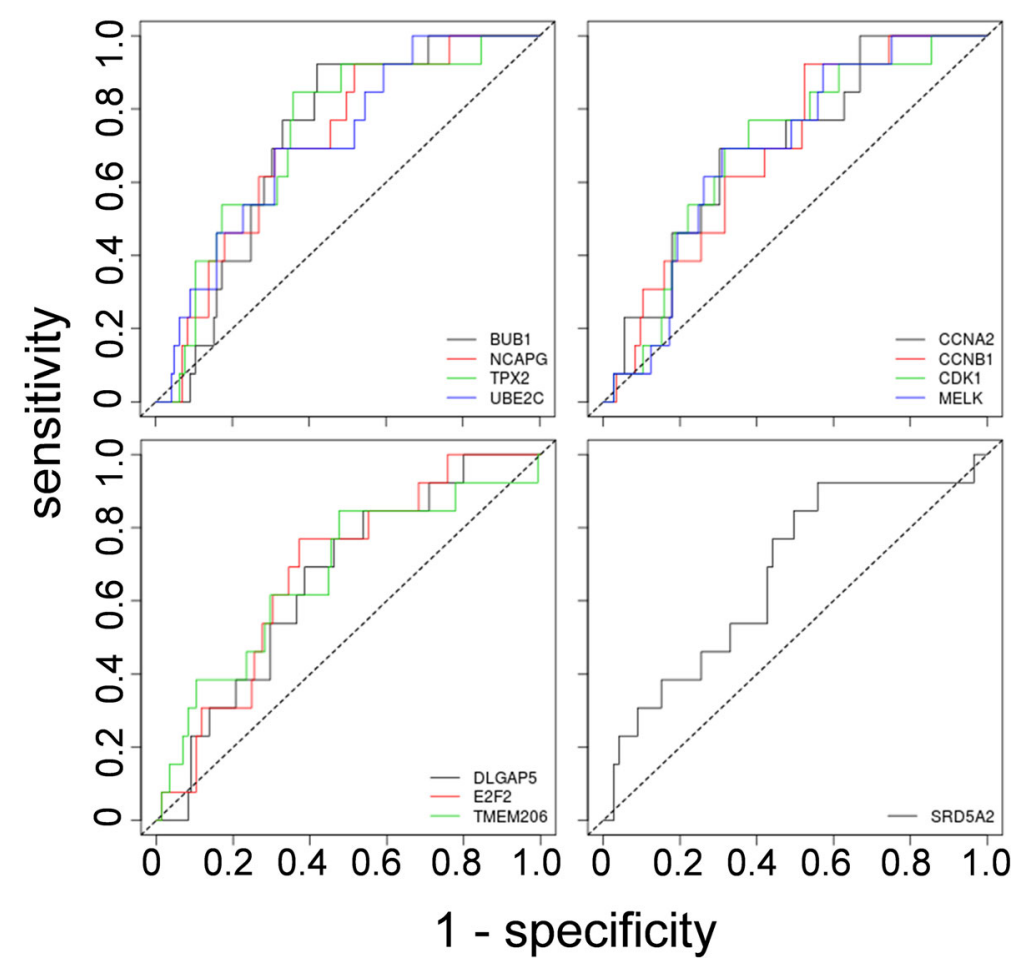

Fig. 2 Receiver Operating Characteristic (ROC) curves for transcripts predicting biochemical recurrence (BCR) in patients with Gleason score 7 tumours. $(n=158)$. BCR predicted by increased (BUB1, NCAPG, TPX2, UBE2C, CCNA2, CCNB1, CDK1, MELK, DLGAP5, E2F2, TMEM206), or decreased (SRD5A2) abundance of transcripts. See Table 2 for details. AUC-Area under the curve. Data from TCGA-PRAD (TCGA, 2015) 


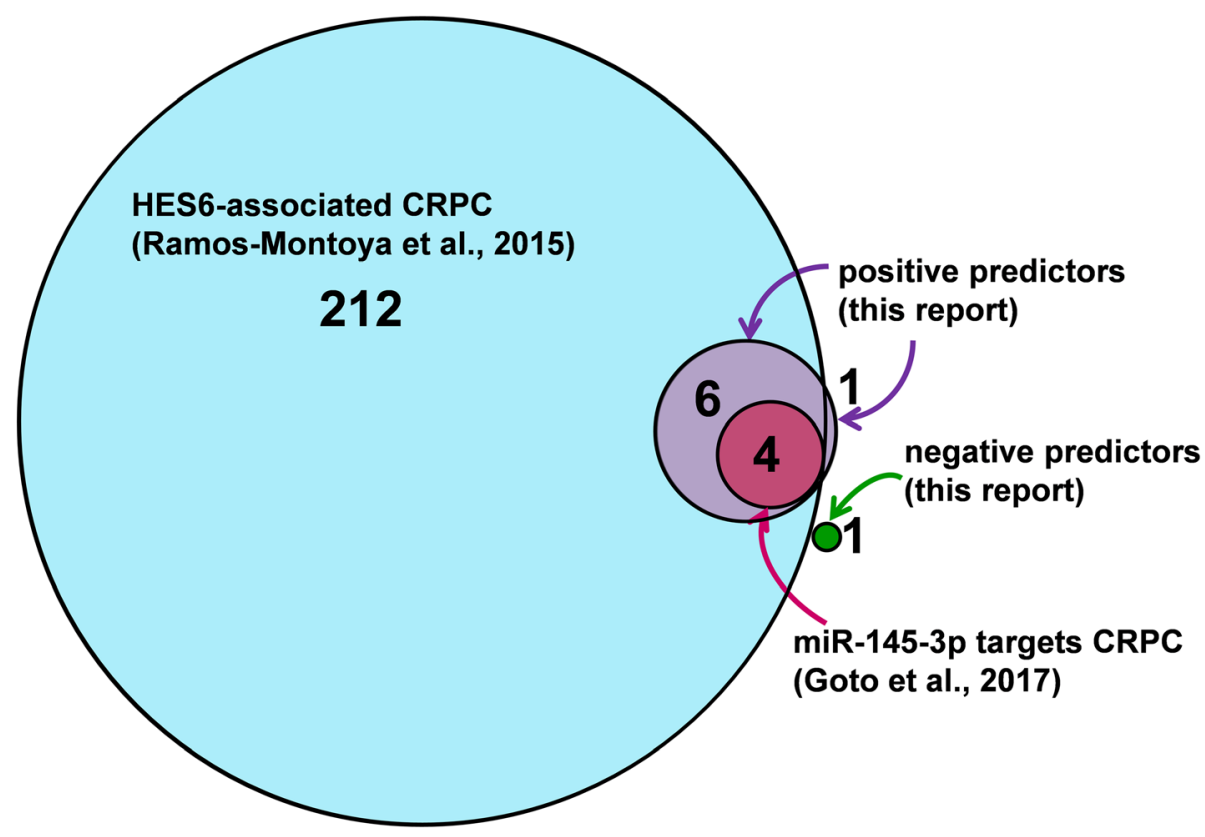

Fig. 3 The positive predictors of BCR in Gleason score 7 tumours also predict castration-resistant prostate cancer (CRPC). Ten of 11 positive predictors identified in this study encode cell cycle and mitosis proteins that are part of a HES6-associated E2F1-dependent signature of castration-resistant prostate cancer (CRPC). Four of the 10 are targeted by the miRNA miR-145-3p in CRPC. Total of numbers within or adjacent to each circle are the number of prognostic transcripts in each dataset

Table 3 Univariate logistic regression and ROC-AUC analyses for predicting BCR in patients with Gleason score $3+4=7$ tumours

\begin{tabular}{|c|c|c|c|c|c|c|c|c|c|c|c|}
\hline Variable & Odds Ratio (OR) & $95 \% \mathrm{Cl}$ OR & $P$ value $O R$ & ROC-AUC & SE AUC & $P$ value AUC & Youden cut-off & Sensitivity & Specificity & PPV & NPV \\
\hline \multicolumn{12}{|c|}{ (up in tumour) } \\
\hline BUB1 & 1.93 & $1.029-3.604$ & 4.03E-02 & 0.865 & 0.045 & 4.75E-16 & 1.54 & 1.000 & 0.78 & 0.22 & 1.00 \\
\hline TPX2 & 1.40 & $1.055-1.852$ & $1.98 \mathrm{E}-02$ & 0.872 & 0.060 & 5.07E-10 & 4.09 & 1.000 & 0.74 & 0.19 & 1.00 \\
\hline NCAPG & 2.72 & $1.071-6.915$ & $3.55 \mathrm{E}-02$ & 0.855 & 0.067 & $1.23 \mathrm{E}-07$ & 1.33 & 0.800 & 0.83 & 0.22 & 0.99 \\
\hline UBE2C & 1.20 & $1.051-1.369$ & 7.00E-03 & 0.889 & 0.050 & $7.21 \mathrm{E}-15$ & 7.79 & 1.000 & 0.80 & 0.23 & 1.00 \\
\hline MELK & 1.72 & $0.939-3.152$ & 7.89E-02 & 0.819 & 0.082 & 1.03E-04 & 2.17 & 0.800 & 0.86 & 0.25 & 0.99 \\
\hline CCNA2 & 1.83 & $1.113-3.000$ & $1.71 \mathrm{E}-02$ & 0.810 & 0.106 & 3.39E-03 & 2.63 & 0.800 & 0.80 & 0.19 & 0.99 \\
\hline CCNB1 & 1.63 & $1.109-2.383$ & 1.27E-02 & 0.824 & 0.083 & 1.00E-04 & 4.69 & 1.000 & 0.57 & 0.12 & 1.00 \\
\hline CDK1 & 1.28 & $1.070-1.532$ & $6.80 \mathrm{E}-03$ & 0.863 & 0.090 & $5.50 \mathrm{E}-05$ & 7.32 & 0.800 & 0.90 & 0.33 & 0.99 \\
\hline E2F2 & 5.98 & $0.824-43.408$ & 7.70E-02 & 0.720 & 0.119 & $6.39 \mathrm{E}-02$ & 0.37 & 0.800 & 0.70 & 0.14 & 0.98 \\
\hline DLGAP5 & 1.95 & $0.954-3.984$ & $6.73 \mathrm{E}-02$ & 0.855 & 0.066 & $6.61 \mathrm{E}-08$ & 0.86 & 1.000 & 0.64 & 0.14 & 1.00 \\
\hline TMEM206 & 0.98 & $0.766-1.243$ & $8.40 \mathrm{E}-01$ & 0.545 & 0.154 & 7.72E-01 & 9.11 & 0.800 & 0.52 & 0.09 & 0.98 \\
\hline CDKN3 & 1.50 & $1.071-2.108$ & 1.85E-02 & 0.708 & 0.187 & 2.65E-01 & 6.47 & 0.600 & 0.95 & 0.43 & 0.98 \\
\hline SHMT2 & 1.03 & $0.983-1.075$ & 2.21E-01 & 0.740 & 0.093 & $9.94 \mathrm{E}-03$ & 60.61 & 0.800 & 0.71 & 0.14 & 0.98 \\
\hline \multicolumn{12}{|c|}{ (down in tumour) } \\
\hline SRD5A2 & 0.58 & $0.367-0.921$ & 2.09E-02 & 0.884 & 0.079 & 1.03E-06 & 3.75 & 0.800 & 0.88 & 0.29 & 0.99 \\
\hline CSRP1 & 1.00 & $0.992-1.001$ & $9.71 \mathrm{E}-02$ & 0.752 & 0.132 & 5.66E-02 & 417.97 & 0.800 & 0.80 & 0.19 & 0.99 \\
\hline PGM5 & 0.97 & $0.930-1.007$ & $1.04 \mathrm{E}-01$ & 0.745 & 0.136 & 7.28E-02 & 18.57 & 0.600 & 0.90 & 0.27 & 0.97 \\
\hline NFIB & 0.98 & $0.903-1.054$ & $5.26 \mathrm{E}-01$ & 0.578 & 0.129 & $5.45 E-01$ & 24.07 & 0.600 & 0.72 & 0.12 & 0.97 \\
\hline
\end{tabular}

Data are from TCGA-PRAD (TCGA, 2015). $n=88$. Cl-confidence interval, SE-standard error. Youden cut-off is the optimal point to separate biochemical recurrence $(B C R)$ from non-BCR. PPV-positive predictive value, NPV-negative predictive value 
encodes a mitotic checkpoint Ser/Thr kinase that has recently been implicated as a key regulator of prostate cancer progression [60]. TPX2 was also a top prognosticator and is a microtubule-associated protein that stimulates Ran-GTP-dependent microtubule nucleation and regulates Aurora A kinase during mitosis and cell cycle progression [61, 62]. Elevated expression of TPX2 is a common finding in human cancers, including prostate, and overexpression in vitro increases invasion of multiple cancer cell lines [63-65]. Like BUB1 and TPX2, the other transcripts positively associated with BCR function in the cell cycle and/or mitosis. Elevated abundance of cell cycle and mitosis transcripts has previously been shown to predict $\mathrm{PCa}$ outcome, and is the basis of the Prolaris commercial test for predicting $\mathrm{PCa}$ aggressiveness [21].

The cell cycle and mitosis genes identified here are associated with HES6-dependent E2F1 transcription factor-mediated CRPC [25]. HES6 is a transcription cofactor that physically interacts with E2F1 as well as the androgen receptor [25]. During the G1/S transition, cyclin-dependent kinases and cyclins phosphorylate the tumour suppressor retinoblastoma, resulting in a weakening of its interaction with E2F proteins [66]. E2F2 (as well as E2F1 and E2F3a) are then free to activate genes that promote $S$ phase entry and cell cycle progression. In CRPC, HES6 is able to maintain androgen receptor activity in the absence of testosterone. In the current study E2F2, but not E2F1, was found to be prognostic for BCR, indicating E2F2 may be a more sensitive or earlier indicator of poor clinical outcome than the related family member, E2F1.

E2F2 transcription factor has been shown previously to be negatively regulated by the Let- 7 family miRNA, MIRLET7A, leading to suppression of growth of PCa cells [67]. miRNAs are small RNA molecules that are bound by Argonaute proteins to form an RNA-induced silencing complex that targets specific mRNA(s), typically leading to translational repression [68]. The abundance of many miRNA is altered in $\mathrm{PCa}$, and is prognostic for clinical outcome [69]. Some miRNA, such as MIRLET7A, act as tumour suppressors by targeting genes (e.g. E2F2), that enhance tumour growth. In contrast, others act as oncogenes by targeting tumour suppressors or cell death and differentiation pathway mRNAs [70]. MIR145-3P, a tumour suppressive miRNA, is decreased modestly in hormone-sensitive PCa, and decreased severely in CRPC, and low levels are associated with a shorter time to BCR [71]. Examining MIR145-3P in detail, Goto et al. identified four key MIR145-3P targets (BUB1, NCAPG, CDK1, MELK) [23]. All four are upregulated in hormone-sensitive PCa, and elevated even more in CRPC, and all are part of the group of cell cycle and mitosis genes identified in the current study, both in Gleason score 7, and in the
Gleason score $3+4=7$ subgroup. Given that thousands of proteins participate in the cell division cycle [72], the specific identification of BUB1, NCAPG, CDK1, and MELK as predictors of BCR, as well as key targets of MIR145-3P that are associated with CRPC, suggests a particularly important role for these cell cycle/mitosis genes in aggressive PCa.

Like other cancers, PCa frequently exhibits defects in cell cycle regulation and cell cycle progression and cell cycle proteins have been explored as therapeutic targets [73]. For example, prostate cancer Phase IB/II trials are ongoing for the CDK4/6 inhibitors ribociclib (ClinicalTrials.gov identifier: NCT02555189, NCT02494921) and palbociclib (NCT02905318, NCT02059213), and the CHEK1 inhibitor LY2606368 (NCT02203513). The cell cycle and mitosis proteins we identified in the present study do not include CDK4/6 or CHEK1. However, almost half are targets of MIRLET7A or MIR145-3P tumour suppressor miRNA. Pre-clinical and clinical trials are currently underway to determine the feasibility of using synthetic miRNA mimics (to compensate for decreased abundance of endogenous tumour suppressive miRNA) or antimiRNA (to block endogenous oncogenic miRNA) as therapeutic agents [70]. Diseases currently being targeted in clinical trials include hepatitis (NCT02508090, NCT02452814), lymphoma (NCT0250552) and mesothelioma (NCT02369198). The experimental evidence supports an important role in PCa progression of miRNA regulation of E2F2, BUB1, NCAPG, CDK1, and MELK. As such, in future studies it would be interesting to determine if the cell cycle and mitosis transcripts identified in the current study might prove to be effective targets for miRNA-based therapeutics in PCa patients.

SRD5A2 was decreased in tumours and negatively associated with BCR. SRD5A2 encodes a steroid 5- $\alpha$-reductase 2 that converts testosterone to the more potent androgen receptor agonist, dihydrotestosterone. Multivariable logistic regression analysis showed that including CCNB1 or $\mathrm{UBE} 2 \mathrm{C}$ and SRD5A2 as variables improved the predictive power in Gleason $3+4=7$. CCNB1 encodes a cyclin B1 required during mitosis, and $\mathrm{UBE} 2 \mathrm{C}$ encodes an E2 ubiquitin-conjugating enzyme important in cyclin destruction. These findings suggest it may be beneficial to pair predictors from distinct cellular pathways (cell cycle/mitosis plus androgen synthesis) to improve prognostication in Gleason score 3+4=7 PCa. SRD5A2 was previously identified in a candidate screen of $732 \mathrm{PCa}$-related genes [22] and forms part of the commercial Oncotype DX Genomic Prostate Score assay that predicts tumour aggressiveness in low and intermediate risk PCa. SRD5A2 was also identified by Rubicz et al. [50] in an unbiased screen for transcripts that improved prediction of $\mathrm{PCa}$ recurrence following radical prostatectomy when combined with Gleason score. Taken together, these 
findings suggest SRD5A2 may be a robust prognosticator of disease outcome in PCa. However, lower SRD5A2 transcript abundance has previously been reported to be associated with poor [50] or favourable [22] outcome. Moreover, altered SRD5A2 activity resulting from genetic polymorphisms or treatment with drugs such as finasteride has inconsistent effects on PCa outcome [74-76]. Accordingly, additional studies are warranted to clarify the role of SRD5A2 abundance in PCa outcome.

The average patient follow-up time in the TCGA validation dataset was short ( $<2$ years) [35], consistent with the transcripts identified in the current study as prognostic for early, aggressive disease progression. The small number of patients with BCR in this short follow-up time (13/158 Gleason score 7 cases), together with incomplete data for pre-operative PSA, precluded our testing for concurrent, independent roles for transcript abundance and PSA in the multivariable logistic regression analysis. In the future, prospective studies that include a larger number of patients with complete clinical information and long-term follow-up (15 years+) would be helpful to determine if the improvement in risk stratification we identified here is durable and reproducible.

\section{Conclusions}

In this study we identify SRD5A2, and 11 mitosis and cell cycle transcripts that predict $\mathrm{PCa}$ disease progression in patients with Gleason score 7 disease. The prognostic power of 10 of these transcripts extended to patients with Gleason $3+4=7$ disease indicating they are excellent candidates for stratifying risk in this group of patients with disease that is often deemed likely to have a favourable outcome. Future studies, especially those including longterm clinical follow-up, will be helpful to confirm the robustness of their predictive power, as well as the therapeutic potential for pharmacologic or genetic intervention.

\section{Additional files}

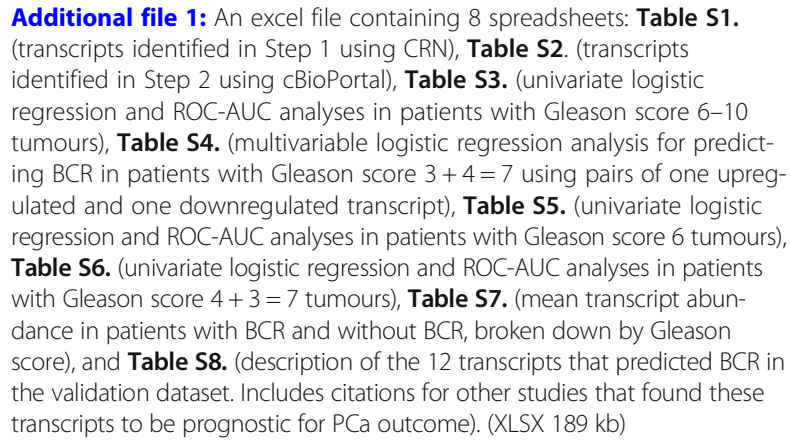

Additional file 2: Figure S1. showing ROC-AUC for test transcripts in patients with Gleason score 6-10 tumours. (JPG $1535 \mathrm{~kb}$ )

\section{Abbreviations}

BCR: Biochemical recurrence; CRPC: Castration-resistant prostate cancer; miRNA: microRNA; OR: Odds ratio; PCa: Prostate cancer; PSA: Prostate-specific antigen; ROC-AUC: Receiver operating characteristic area under the curve;

TPM: Transcripts per million

\section{Acknowledgements}

The authors thank Dr. Haiyan Jiang, Senior Biostatistician, University Health Network, Toronto, Canada, for statistical help in generating univariate and multivariable models.

\section{Funding}

The Princess Margaret Cancer Foundation.

Availability of data and materials

All data analysed in this study are publicly available.

\section{Authors' contributions}

WLJ designed the study, analysed the data, and drafted the manuscript. CJS and CNC conceived the study and revised the manuscript critically for intellectual content. All authors read and approved the final manuscript.

Ethics approval and consent to participate

Not applicable.

Consent for publication

Not applicable.

\section{Competing interests}

The authors declare that they have no competing interests.

\section{Publisher's Note}

Springer Nature remains neutral with regard to jurisdictional claims in published maps and institutional affiliations.

\section{Author details}

${ }^{1}$ Radiation Medicine Program, Princess Margaret Cancer Centre, University Health Network, Toronto, ON, Canada. ²Department of Radiation Oncology, University of Toronto, Toronto, ON, Canada. ${ }^{3}$ Lunenfeld-Tanenbaum Research Institute, Mount Sinai Hospital, Toronto, ON, Canada. ${ }^{4}$ Department of Surgery, University of Toronto, Toronto, ON, Canada. ${ }^{5}$ Institute of Medical Science, University of Toronto, Toronto, ON, Canada. ${ }^{6}$ Laboratory Medicine and Pathobiology, University of Toronto, Toronto, ON, Canada.

Received: 24 April 2018 Accepted: 20 December 2018

Published online: 07 January 2019

References

1. Torre LA, Bray F, Siegel RL, Ferlay J, Lortet-Tieulent J, Jemal A. Global cancer statistics, 2012. CA Cancer J Clin. 2015;65(2):87-108.

2. Attard G, Parker C, Eeles RA, Schroder F, Tomlins SA, Tannock I, et al. Prostate cancer. Lancet. 2016;387(10013):70-82.

3. Canadian Cancer Statistics Advisory Committee. Canadian Cancer Statistics 2017. Toronto, ON: 2017 2017. Report No.

4. Brockman JA, Alanee S, Vickers AJ, Scardino PT, Wood DP, Kibel AS, et al. Nomogram predicting prostate Cancer-specific mortality for men with biochemical recurrence after radical prostatectomy. Eur Urol. 2015;67(6): 1160-7.

5. Stephenson AJ, Kattan MW, Eastham JA, Dotan ZA, Bianco FJ Jr, Lilja H, et al Defining biochemical recurrence of prostate cancer after radical prostatectomy: a proposal for a standardized definition. J Clin Oncol. 2006; 24(24):3973-8

6. Freedland SJ, Humphreys EB, Mangold LA, Eisenberger M, Dorey FJ, Walsh PC, et al. Risk of prostate cancer-specific mortality following biochemical recurrence after radical prostatectomy. JAMA. 2005;294(4):433-9.

7. Anscher MS. PSA kinetics and risk of death from prostate cancer: in search of the holy grail of surrogate end points. JAMA. 2005;294(4):493-4.

8. Bianco FJ Jr, Scardino PT, Eastham JA. Radical prostatectomy: long-term cancer control and recovery of sexual and urinary function ("trifecta"). Urology. 2005;66(5 Suppl):83-94. 
9. Stuchbery R, McCoy PJ, Hovens CM, Corcoran NM. Androgen synthesis in prostate cancer: do all roads lead to Rome? Nature Reviews Urology. 2017; 14(1):49-58

10. Mottet N, Bellmunt J, Bolla M, Briers E, Cumberbatch MG, De Santis M, et al. EAU-ESTRO-SIOG guidelines on prostate Cancer. Part 1: screening, diagnosis, and local treatment with curative intent. Eur Urol. 2017;71(4): 618-29.

11. Mohler JL, Armstrong AJ, Bahnson RR, D'Amico AV, Davis BJ, Eastham JA, et al. Prostate Cancer, version 1.2016. J Natl Compr Canc Netw. 2016;14(1):19-30.

12. D'Amico AV, Whittington R, Malkowicz SB, Schultz D, Blank K, Broderick GA, et al. Biochemical outcome after radical prostatectomy, external beam radiation therapy, or interstitial radiation therapy for clinically localized prostate cancer. JAMA. 1998;280(11):969-74

13. Stark JR, Perner S, Stampfer MJ, Sinnott JA, Finn S, Eisenstein AS, et al, Gleason score and lethal prostate cancer: does $3+4=4+3$ ? J Clin Oncol. 2009;27(21):3459-64.

14. Zumsteg ZS, Spratt DE, Pei I, Zhang Z, Yamada Y, Kollmeier M, et al. A new risk classification system for therapeutic decision making with intermediaterisk prostate cancer patients undergoing dose-escalated external-beam radiation therapy. Eur Urol. 2013:64(6):895-902.

15. Gnanapragasam VJ, Lophatananon A, Wright KA, Muir KR, Gavin A, Greenberg DC. Improving clinical risk stratification at diagnosis in primary prostate Cancer: a prognostic modelling study. PLoS Med. 2016;13(8): e1002063.

16. Jensen MA, Ferretti V, Grossman RL, Staudt LM. The NCl genomic data commons as an engine for precision medicine. Blood. 2017;130(4):453-9.

17. Metzker ML. Sequencing technologies - the next generation. Nat Rev Genet 2010;11(1):31-46.

18. Gaudreau PO, Stagg J, Soulieres D, Saad F. The present and future of biomarkers in prostate Cancer: proteomics, genomics, and immunology advancements. Biomark Cancer. 2016;8(Suppl 2):15-33.

19. Lamy PJ, Allory Y, Gauchez AS, Asselain B, Beuzeboc P, de Cremoux P, et al. Prognostic biomarkers used for localised prostate Cancer management: a systematic review. Eur Urol Focus. 2017

20. Sharma P, Zargar-Shoshtari K, Pow-Sang JM. Biomarkers for prostate cancer: present challenges and future opportunities. Future Science OA. 2016;2(1):FSO72

21. Cuzick J, Swanson GP, Fisher G, Brothman AR, Berney DM, Reid JE, et al. Prognostic value of an RNA expression signature derived from cell cycle proliferation genes in patients with prostate cancer: a retrospective study. Lancet Oncol. 2011;12(3):245-55.

22. Klein EA, Cooperberg MR, Magi-Galluzzi C, Simko JP, Falzarano SM, Maddala T, et al. A 17-gene assay to predict prostate cancer aggressiveness in the context of Gleason grade heterogeneity, tumor multifocality, and biopsy undersampling. Eur Urol. 2014;66(3):550-60.

23. Goto Y, Kurozumi A, Arai T, Nohata N, Kojima S, Okato A, et al. Impact of novel miR-145-3p regulatory networks on survival in patients with castration-resistant prostate cancer. Br J Cancer. 2017:117(3):409-20.

24. Jia Z, Rahmatpanah FB, Chen X, Lernhardt W, Wang Y, Xia XQ, et al. Expression changes in the stroma of prostate cancer predict subsequent relapse. PLoS One. 2012;7(8):e41371.

25. Ramos-Montoya A, Lamb AD, Russell R, Carroll T, Jurmeister S, GaleanoDalmau N, et al. HES6 drives a critical AR transcriptional programme to induce castration-resistant prostate cancer through activation of an E2F1mediated cell cycle network. EMBO Mol Med. 2014;6(5):651-61.

26. Li JR, Sun CH, Li W, Chao RF, Huang CC, Zhou XJ, et al. Cancer RNA-Seq Nexus: a database of phenotype-specific transcriptome profiling in cancer cells. Nucleic Acids Res. 2016;44(D1):D944-51.

27. Huang da W, Sherman BT, Lempicki RA. Systematic and integrative analysis of large gene lists using DAVID bioinformatics resources. Nat Protoc 2009; 4(1):44-57.

28. Huang da W, Sherman BT, Lempicki RA. Bioinformatics enrichment tools: paths toward the comprehensive functional analysis of large gene lists. Nucleic Acids Res 2009;37(1):1-13.

29. Gao J, Aksoy BA, Dogrusoz U, Dresdner G, Gross B, Sumer SO, et al. Integrative analysis of complex cancer genomics and clinical profiles using the cBioPortal. Sci Signal. 2013;6(269):pl1.

30. Cerami E, Gao J, Dogrusoz U, Gross BE, Sumer SO, Aksoy BA, et al. The cBio cancer genomics portal: an open platform for exploring multidimensional cancer genomics data. Cancer Discov. 2012;2(5):401-4.
31. Taylor BS, Schultz N, Hieronymus H, Gopalan A, Xiao Y, Carver BS, et al. Integrative genomic profiling of human prostate cancer. Cancer Cell. 2010; 18(1):11-22

32. Dunning MJ, Vowler SL, Lalonde $E$, Ross-Adams $H$, Boutros $P$, Mills IG, et al. Mining human prostate Cancer datasets: the "camcAPP" shiny app. EBioMedicine. 2017:17:5-6.

33. Ross-Adams H, Lamb AD, Dunning MJ, Halim S, Lindberg J, Massie CM, et al. Integration of copy number and transcriptomics provides risk stratification in prostate cancer: a discovery and validation cohort study. EBioMedicine. 2015;2(9):1133-44.

34. Hothorn T, Hornik K, Zeileis A. Unbiased recursive partitioning: a conditional inference framework. J Comput Graph Stat. 2006;15(3):651-74.

35. Cancer Genome Atlas Research Network. The molecular taxonomy of primary prostate Cancer. Cell. 2015;163(4):1011-25.

36. Goksuluk D, Korkmaz S, Zarasiz G, Karaagaoglu AE. easyROC: an interactive web-tool for ROC curve analysis using $\mathrm{R}$ language environment. The $\mathrm{R}$ journal. 2016:8(2):213-30.

37. Agell L, Hernandez S, Nonell L, Lorenzo M, Puigdecanet E, de Muga S, et al. A 12-gene expression signature is associated with aggressive histological in prostate cancer: SEC14L1 and TCEB1 genes are potential markers of progression. Am J Pathol. 2012;181(5):1585-94.

38. Bibikova M, Chudin E, Arsanjani A, Zhou L, Garcia EW, Modder J, et al. Expression signatures that correlated with Gleason score and relapse in prostate cancer. Genomics. 2007;89(6):666-72.

39. Bismar TA, Demichelis F, Riva A, Kim R, Varambally S, He L, et al. Defining aggressive prostate cancer using a 12-gene model. Neoplasia. 2006:8(1):59-68

40. Chen X, Xu S, McClelland M, Rahmatpanah F, Sawyers A, Jia Z, et al. An accurate prostate cancer prognosticator using a seven-gene signature plus Gleason score and taking cell type heterogeneity into account. PLoS One. 2012;7(9):e45178.

41. Erho N, Crisan A, Vergara IA, Mitra AP, Ghadessi M, Buerki C, et al. Discovery and validation of a prostate cancer genomic classifier that predicts early metastasis following radical prostatectomy. PLoS One. 2013;8(6):e66855.

42. Glinsky GV, Berezovska O, Glinskii AB. Microarray analysis identifies a deathfrom-cancer signature predicting therapy failure in patients with multiple types of cancer. J Clin Invest. 2005;115(6):1503-21.

43. Irshad S, Bansal M, Castillo-Martin M, Zheng T, Aytes A, Wenske S, et al. A molecular signature predictive of indolent prostate cancer. Sci Transl Med. 2013;5(202):202ra122.

44. Long Q, Johnson BA, Osunkoya AO, Lai YH, Zhou W, Abramovitz M, et al. Protein-coding and microRNA biomarkers of recurrence of prostate cancer following radical prostatectomy. Am J Pathol. 2011;179(1):46-54.

45. Long Q, Xu J, Osunkoya AO, Sannigrahi S, Johnson BA, Zhou W, et al. Global transcriptome analysis of formalin-fixed prostate cancer specimens identifies biomarkers of disease recurrence. Cancer Res. 2014;74(12):3228-37.

46. Luca BA, Brewer DS, Edwards DR, Edwards S, Whitaker HC, Merson S, et al. DESNT: A Poor Prognosis Category of Human Prostate Cancer. European urology focus. 2017.

47. Rajan P, Stockley J, Sudbery IM, Fleming JT, Hedley A, Kalna G, et al. Identification of a candidate prognostic gene signature by transcriptome analysis of matched pre- and post-treatment prostatic biopsies from patients with advanced prostate cancer. BMC Cancer. 2014;14:977.

48. Ramaswamy S, Ross KN, Lander ES, Golub TR. A molecular signature of metastasis in primary solid tumors. Nat Genet. 2003:33(1):49-54.

49. Romanuik TL, Ueda T, Le N, Haile S, Yong TM, Thomson T, et al. Novel biomarkers for prostate cancer including noncoding transcripts. Am J Pathol. 2009;175(6):2264-76.

50. Rubicz R, Zhao S, Wright JL, Coleman I, Grasso C, Geybels MS, et al. Gene expression panel predicts metastatic-lethal prostate cancer outcomes in men diagnosed with clinically localized prostate cancer. Mol Oncol. 2017; 11(2):140-50.

51. Sharma NL, Massie CE, Ramos-Montoya A, Zecchini V, Scott HE, Lamb AD, et al. The androgen receptor induces a distinct transcriptional program in castration-resistant prostate cancer in man. Cancer Cell. 2013;23(1):35-47.

52. Varambally S, Yu J, Laxman B, Rhodes DR, Mehra R, Tomlins SA, et al. Integrative genomic and proteomic analysis of prostate cancer reveals signatures of metastatic progression. Cancer Cell. 2005;8(5):393-406.

53. Wu CL, Schroeder BE, Ma XJ, Cutie CJ, Wu S, Salunga R, et al. Development and validation of a 32-gene prognostic index for prostate cancer progression. Proc Natl Acad Sci U S A. 2013;110(15):6121-6. 
54. Yu J, Yu J, Rhodes DR, Tomlins SA, Cao X, Chen G, et al. A polycomb repression signature in metastatic prostate cancer predicts cancer outcome. Cancer Res. 2007;67(22):10657-63.

55. Jhun MA, Geybels MS, Wright JL, Kolb S, April C, Bibikova M, et al. Gene expression signature of Gleason score is associated with prostate cancer outcomes in a radical prostatectomy cohort. Oncotarget. 2017;8(26):43035-47.

56. Sunkel B, Wu D, Chen Z, Wang CM, Liu X, Ye Z, et al. Integrative analysis identifies targetable CREB1/FoxA1 transcriptional co-regulation as a predictor of prostate cancer recurrence. Nucleic Acids Res. 2016;44(9):4105-22.

57. Micallef L, Rodgers P. eulerAPE: drawing area-proportional 3-Venn diagrams using ellipses. PloS One. 2014;9(7):e101717.

58. Zhao J, Zhu D, Zhang X, Zhang Y, Zhou J, Dong M. TMEM206 promotes the malignancy of colorectal cancer cells by interacting with AKT and extracellular signal-regulated kinase signaling pathways. J Cell Physiol. 2018. https://doi.org/10.1002/jcp.27751.

59. Morlacco A, Cheville JC, Rangel LJ, Gearman DJ, Karnes RJ. Adverse Disease Features in Gleason Score 3 + 4 "Favorable Intermediate-Risk" Prostate Cancer: Implications for Active Surveillance. Eur Urol. 72(3):442-7.

60. Jurmeister S, Ramos-Montoya A, Sandi C, Pertega-Gomes N, Wadhwa K, Lamb AD, et al. Identification of potential therapeutic targets in prostate cancer through a cross-species approach. EMBO Mol Med. 2018;10:e8274. https://doi.org/10.15252/emmm.201708274.

61. Neumayer G, Belzil C, Gruss OJ, Nguyen MD. TPX2: of spindle assembly, DNA damage response, and cancer. Cell Mol Life Sci. 2014;71(16):3027-47.

62. Zhang R, Roostalu J, Surrey T, Nogales E. Structural insight into TPX2stimulated microtubule assembly. Elife. 2017;6:e30959. https://doi.org/10 7554/elife.30959.

63. Gu JJ, Zhang JH, Chen HJ, Wang SS. TPX2 promotes glioma cell proliferation and invasion via activation of the AKT signaling pathway. Oncol Lett. 2016; 12(6):5015-22

64. Hsu CW, Chen YC, Su HH, Huang GJ, Shu CW, Wu TT, et al. Targeting TPX2 suppresses the tumorigenesis of hepatocellular carcinoma cells resulting in arrested mitotic phase progression and increased genomic instability. J Cancer. 2017:8(8):1378-94.

65. Pan HW, Su HH, Hsu CW, Huang GJ, Wu TT. Targeted TPX2 increases chromosome missegregation and suppresses tumor cell growth in human prostate cancer. OncoTargets and therapy. 2017;10:3531-43.

66. Ruijtenberg S, van den Heuvel S. Coordinating cell proliferation and differentiation: antagonism between cell cycle regulators and cell typespecific gene expression. Cell Cycle. 2016;15(2):196-212.

67. Dong Q, Meng P, Wang T, Qin W, Qin W, Wang F, et al. MicroRNA let-7a inhibits proliferation of human prostate cancer cells in vitro and in vivo by targeting E2F2 and CCND2. PLoS One. 2010;5(4):e10147.

68. Wilczynska A, Bushell M. The complexity of miRNA-mediated repression. Cell Death Differ. 2015;22(1):22-33.

69. Kanwal R, Plaga AR, Liu X, Shukla GC, Gupta S. MicroRNAs in prostate cancer: functional role as biomarkers. Cancer Lett. 2017:407:9-20.

70. Rupaimoole R, Slack FJ. MicroRNA therapeutics: towards a new era for the management of cancer and other diseases. Nat Rev Drug Discov. 2017;16(3): 203-22.

71. Coarfa C, Fiskus W, Eedunuri VK, Rajapakshe K, Foley C, Chew SA, et al, Comprehensive proteomic profiling identifies the androgen receptor axis and other signaling pathways as targets of microRNAs suppressed in metastatic prostate cancer. Oncogene. 2016;35(18):2345-56.

72. Santos A, Wernersson R, Jensen LJ. Cyclebase 3.0: a multi-organism database on cell-cycle regulation and phenotypes. Nucleic Acids Res. 2015; 43(Database issue):D1140-4.

73. Otto T, Sicinski P. Cell cycle proteins as promising targets in cancer therapy. Nat Rev Cancer. 2017;17(2):93-115.

74. Cussenot O, Azzouzi AR, Nicolaiew N, Mangin P, Cormier L, Fournier G, et al. Low-activity V89L variant in SRD5A2 is associated with aggressive prostate cancer risk: an explanation for the adverse effects observed in chemoprevention trials using 5-alpha-reductase inhibitors. Eur Urol. 2007;52(4):1082-7.

75. Maier C. Editorial comment on: low-activity V89L variant in SRD5A2 is associated with aggressive prostate cancer risk: an explanation for the adverse effects observed in chemoprevention trials using 5-alpha-reductase inhibitors. Eur Urol. 2007;52(4):1088-9.

76. Prayer-Galetti T. Editorial comment on: low-activity V89L variant in SRD5A2 is associated with aggressive prostate cancer risk: an explanation for the adverse effects observed in chemoprevention trials using 5-alpha-reductase inhibitors. Eur Urol. 2007;52(4):1087-8.

Ready to submit your research? Choose BMC and benefit from:

- fast, convenient online submission

- thorough peer review by experienced researchers in your field

- rapid publication on acceptance

- support for research data, including large and complex data types

- gold Open Access which fosters wider collaboration and increased citations

- maximum visibility for your research: over $100 \mathrm{M}$ website views per year

At $\mathrm{BMC}$, research is always in progress.

Learn more biomedcentral.com/submissions 